\title{
THE NETWORKING PRACTICES OF BUSINESSWOMEN
}

\author{
Marlene Bogaards: School of Business Management, North-West University \\ Saskia de Klerk: School of Business Management, North-West University \\ Karina Mostert: School of Human Resources Sciences, North-West University
}

\begin{abstract}
Synopsis
Purpose: The primary objective of this study was to investigate the networking practices of businesswomen in the Gauteng Province, South Africa. The study of businesswomen's networking practices can provide critical insight into the manner in which networking can assist businesswomen in personal and professional skills development.
\end{abstract}

Problem investigated: An investigation was conducted into the manner in which the concepts of networking and social networking are perceived by businesswomen in Gauteng. The study further investigated the motivation behind businesswomen's networking practices and the contents of their social networks were explored.

Design/methodology/approach: A non-probability purposive sample, followed by snowball sampling, was used to select businesswomen for in-depth interviews $(n=31)$. In-depth interviews were used as a qualitative method to investigate the networking practices of these participants.

Findings: The results indicate that businesswomen have various perceptions regarding the concepts of networking and social networking. It was also found that businesswomen include certain types of people in their social networks and that they receive various business and personal benefits when their networking is focused (having a clear objective to networking).

Originality/value: These findings provide a background to the manner in which businesswomen perceive networking and social networking. This can serve as a basis for training initiatives to raise businesswomen's awareness of networking and social networking. Aforementioned may also provide insight into the meaning this may hold for them in their work and personal lives (for example, obtaining insight into the manner in which networking can be used to obtain business and personal support). Information derived from this study can further be utilised by businesswomen to assist them in social network development.

Conclusion: It was concluded from the study that businesswomen perceive networking and social networking in various ways (for example, that networking is a skill that can be learnt and that social networking is a way in which individuals can develop friendships). It was further concluded that businesswomen derive various business and personal benefits from their networks, and that businesswomen include various kinds of people in their networks, including supportive people and people with similar values. It was also concluded that business contacts can be found in social environments.

Keywords: networking, networks, social networking, social networks, businesswomen, Gauteng, South Africa

\section{INTRODUCTION}

Networking is a dynamic, ever-changing process (Boe \& Youngs, 1989:9) that involves the development and maintenance of personal and professional relationships with the intention of sharing information that will mutually benefit the role-players involved (Boe, 1994:9; Tullier, 2004:9). Networks can serve as a safety net for individuals and provide moral support when personal changes take place (for example, when changing jobs or career paths, or moving to a new city). Individuals can utilise networks to gain social support, to develop new friendships, and to develop additional interests. Networks are also viewed as an important tool for individuals to utilise should they require career advice (Boe, 1994:9; Forret \& Sullivan, 2002:252).

The study of networking amongst businesswomen is critical, as it can provide important insight into the manner in which networking may be used to assist businesswomen in obtaining further learning opportunities, developing their personal skills, making social contacts and increasing their self-confidence (Travers, Pemberton \& Stevens, 1997:63-65). The above-mentioned is vital if women are to progress in the business environment in which men are still seen as the dominant group (Lahtinen \& Wilson, 1994:16; Linehan, 2001:828). Research conducted by the Businesswomen's Association found that women in 
South Africa only constitute $19.3 \%$ of executive manager positions, and $16.6 \%$ of director positions (Businesswomen's Association, 2010).

The objective of this study was to develop an improved understanding of the networking practices of businesswomen in Gauteng. Gauteng was selected as the region of study, as it is viewed as the heart of South Africa's commercial business and economic sectors (SA, 2009). A large number of businesses at which businesswomen are employed are also situated in this province (SA, 2009). The above-mentioned objective was achieved by means of an investigation into the manner in which businesswomen perceive networking and social networking. The motivation behind their networking practices was also explored and the contents of their social networks investigated. The research findings of this in-depth investigation into networking could form part of training initiatives to introduce businesswomen to the concepts of networking and social networking, and the meaning these may hold in their work and personal lives. The aforementioned is important as this provides businesswomen with insight into the manner in which networking can be utilised in order to obtain business and personal support. In this way, a contribution may be made to the personal and professional development of businesswomen in Gauteng.

\section{THEORETICAL BACKGROUND}

For the purpose of this study, the literature focuses on two main concepts, namely networking and social networking.

\section{Networking}

Networking involves meeting with people, interacting with them and building strong relationships (Bannerman, 2006:15, 20; Boe, 1994:9; Lucas, 1994:20; Misner \& Morgan, 2000:13, 20; Tullier, 2004:31). Individuals network with the intention of building long-term relationships (White, 2004:5). Networks consist of relationships that can be mutually beneficial and engender mutual trust (Lindenfield \& Lindenfield, 2005:13). The contribution of beneficial elements to the relationship-building process is critical (Kay, 2004:171). In networking, individuals share information, ideas, advice, resources and support that can benefit all role-players involved at a personal or professional level (Bannerman, 2006:15; Boe, 1994:9; Misner \& Morgan, 2000:13; Tullier, 2004:30).

Networking is a skill that can be learned (Yeung, 2006:17) or acquired and consistent development (Boe, 1994:7; Kay, 2004:3) is critical for personal success (Rezac, 2005:xiii). The social skills of networking include knowledge, patience, practice and a positive attitude (Rezac, 2005:xiv); and can be acquired by anyone who is willing and ready to work hard (Boe, 1994:8). Networking can be adapted to any situation that involves interaction with other people (Yeung, 2006:22). Although most connections with new people are still made in the traditional way through existing relationships with friends, family and co-workers (Lindenfield \& Lindenfield, 2005:229), networking opportunities can also arise from formal situations (for example, a scheduled networking appointment with someone) and informal situations (for example, an unplanned conversation with someone on a plane, train or bus; Tullier, 2004:31). Further examples of networking opportunities include mothers meeting each other at school events or parental meetings, or women meeting at the dentist, beauty salon or gym (Tullier, 2004:37). Because networking can take place in various environments, individuals need to be open to interacting with people in any situation (Tullier, 2004:37; Yeung, 2006:23).

For the purpose of the current study, networking is defined as the process of building and maintaining relationships with the expectation that the relationships established will be mutually beneficial, in the information, advice, contacts and support (personal and work support) provided and gained from the networking interaction.

\section{Maintaining relationships}

Networking involves not only interacting with people and building relationships, but also maintaining the relationships developed, as this is a critical aspect of ensuring network success (Boe, 1994:9; Lindenfield \& Lindenfield, 2005:13; Tullier, 2004:30). In order for networkers to gain mutual benefits from their networking efforts, their network contacts need to be continually maintained (Boe, 1994:9; Lindenfield \& Lindenfield, 2005:13; Tullier, 2004:9). As different people provide different kinds of support, individuals 
should maintain relationships with a wide variety of people in order to ensure provision is made for all types of support required (Walker, Wasserman \& Wellman, 1993:72).

In networking, individuals should focus on the relationship and not only on the outcome and benefits derived from that relationship (Boe, 1994:72). A balance should be established between developing, maintaining and utilising relationships (Lindenfield \& Lindenfield, 2005:183). Therefore, it is important to establish emotive connections between individuals when networking (Lindenfield \& Lindenfield, 2005:191) and to later use this developed network. This involves getting to know the individual before utilising the networking relationship (Boe, 1994:72; Lindenfield \& Lindenfield, 2005: 191).

Networking is mutually beneficial (Boe, 1994:9; Lindenfield \& Lindenfield, 2005:13) and should be viewed as a reciprocal process. Accordingly, individuals should be willing to give what they have received because reciprocity is a basic principle of networking (Lindenfield \& Lindenfield, 2005:75). Networking does not entail asking people for jobs or using them to gain what is needed (Tullier, 2004:8-9; Yeung, 2006:168). Individuals should first give of themselves to people in their networks, as generosity is regarded as a critical element of strong networks (Lindenfield \& Lindenfield, 2005:75). The ability to nurture and maintain networking relationships constitutes an essential life skill that can contribute to the well-being and happiness of individuals (Rezac, 2005:xii). Such relationships can allow individuals to meet and share experiences with like-minded people (Kay, 2004:12, 19; Nierenberg, 2005:14).

\section{Motivation behind networking}

A well-cultivated and nurtured network can assist individuals in various ways (Michelli \& Straw, 1997:21). Building and maintaining relationships can support and nourish individuals in a personal capacity (Michelli \& Straw, 1997:2); when people feel supported, their well-being is influenced positively (Michelli \& Straw, 1997:8). Networking further provides individuals with the opportunity to build friendships and rapport, and to gain trust, respect and regard for other people (White, 2004:6). It also provides individuals with the opportunity to create positive energy with others, resulting in their considering the individual should a business opportunity arise (White, 2004:5, Yeung, 2006:18). In networking, it is important for individuals to have a goal in mind (Yeung, 2006:19), as networking efforts need to be focused in order to achieve the desired networking outcomes (Nierenberg, 2005:1; Yeung, 2006:19). Additional motivations are discussed below.

\section{Networking as a marketing tool}

Networking is viewed as a marketing tool (Bannerman, 2006:17; Rezac, 2005:120; White, 2004:68) that can be utilised by individuals to market themselves (Kay, 2004:34; White, 2004:6) and their products or services in situations in which the right environment for networking opportunities is created (White, 2004:6).

\section{Networking as a support system}

Individuals' networks can serve as a safety net and help to provide moral support (Boe, 1994:9), as networking involves building foundations for relationships that are mutually supportive and empowering (Boe, 1994:14).

\section{Networking as a means of building new contacts}

When individuals wish to start a new business, it is important for them to build a network of contacts (such as clients, customers and investors) that will be in place at the time of the business start-up. Networking is a tool that can assist individuals in building these contacts (Yeung, 2006:11).

\section{Influence of networking on business practices}

Networking is a tool that individuals utilise when they wish to start a new business or charitable project, search for new investors, expand the customer base of a business, or look for new partners when strategic alliances need to be formed (Lindenfield \& Lindenfield, 2005:24-26). Networking can also assist individuals in increasing business or in advancing their careers (Kay, 2004:34). 


\section{Influence of networking on career development}

Networking is considered an important means through which individuals can take responsibility for their own careers, (Lindenfield \& Lindenfield, 2005:27), as it can assist them in achieving their career goals (Boe, 1994:12) and enhance their professional lives (Lindenfield \& Lindenfield, 2005:22). According to Lindenfield and Lindenfield (2005:23), networking can assist individuals if they wish to change their career direction, or be promoted, or are looking for a new job.

\section{Networking as a means of sharing beneficial information}

Effective networkers are seekers and providers of information (Rezac, 2005:143). When networking, individuals exchange information that is of personal benefit to the role-players involved (for example, asking a neighbour for the name of a good dentist in the area; Tullier, 2004:6-9). When individuals network effectively, they exchange information, advice and support that lead to mutual success (Boe, 1994:150), growth and happiness of the role-players involved (Tullier, 2004:30).

\section{SOCIAL NETWORKING}

Social networks are viewed as an individual's social contacts (Gottlieb, 1981:203; Rezac, 2005:24), and include friends, colleagues and acquaintances (Rezac, 2005:24). A distinction is commonly made between formal and informal networks (Ibarra, 1993:58). A formal network (business network) is seen as a set of formally specified relationships, whereas an informal network (social network) involves patterns of interaction that are more discretionary and the intent of these relationships is work-related or social. Business networks are more structured than other types of networks. Strategic (business) networking takes place when individuals are focused in their networking approach, purposefully seeking out individuals with whom they wish to build relationships, and nurturing those relationships (Lindenfield \& Lindenfield, 2005:15-17). Networking for business purposes is more likely to take place in the context of a business activity than in pleasurable or recreational activities (Lindenfield \& Lindenfield, 2005:183). With informal (social) networks, the interaction between individuals is more flexible (Ibarra, 1993:58). This study focuses on social networks, as these offer businesswomen the resources for much-needed social support (Marcinkus, Whelan-Berry \& Gordon, 2007:90; Walker et al., 1993:71) that they utilise in order to assist them in coping with everyday problems or crises (Walker et al., 1993:71).

Social networking or social interaction results in the building and maintaining of relationships (Lindenfield \& Lindenfield, 2005:13). It is possible for life-long friendships to be built through meeting individuals in non-business environments (such as individuals having dinner at a mutual friend's house). Social networking can take place during social lunches or by attending other social events, such as wine-tasting evenings (Lindenfield \& Lindenfield, 2005:230; Nierenberg, 2005:27; Yeung, 2006:89-90).

Social motivations behind networking include the development of new friendships (Bannerman, 2006:29; Boe, 1994:9). Building friendships is critical, as individuals cannot be effective networkers without being sociable - and this cannot be achieved in the absence of friends (Bannerman, 2006:29). Interacting socially is also important for career development because local community involvement is regarded as an effective way to make career connections. Strong connections are built, for example, through individuals becoming involved in charitable work. Involvement in charitable activities evidences positively regarded characteristics, such as trust, that render people attractive candidates for networking. Participating in clubs (such as sports clubs or health clubs) is also an effective way for individuals to extend their social networks (Lindenfield \& Lindenfield, 2005:232-233).

An individual's network of social relationships can potentially be used for business purposes through the development of commercial exchanges and working alliances, and to obtain career advice and opportunities (Lindenfield \& Lindenfield, 2005:14). Networking opportunities can also arise, for example through interacting with other parents when attending a hockey practice, or through a daily encounter in a lift resulting in an eventual introduction between individuals (Rezac, 2005:114). Networking events within organisations are also a mechanism through which networking opportunities can arise. These can include inviting people to a breakfast meeting, lunch or after-work event; wine tasting with a wine expert in the meeting room; a social gathering to watch a televised budget speech; or a reception for introducing a business associate from another section of the organisation (Rezac, 2005:119). 
Social networks can also serve as a source of support. Individuals can use their personal contacts to help find balance in their lives, as networking provides a strong bridge between personal and professional lives (Boe \& Youngs, 1989:26; Marcinkus et al., 2007:99-100). Individuals' personal networks are critical to their well-being (Michelli \& Straw, 1997:15). The investment, development and maintenance of personal networks are therefore critical (Michelli \& Straw, 1997:15), as these can provide opportunities for support, stimulation, challenges, appreciation, acceptance, involvement and enjoyment (Michelli \& Straw, 1997:20) that can in turn assist in maintaining balance. It is also important for individuals to maintain relationships with others in their support network to prevent them from feeling exploited (Boe, 1994:153).

\section{Contents of social networks}

Social networks consist of groups of individuals who are interconnected, have similar purposes (Braude \& Francisco-La Grange, 1993:14) and are providers of social support (Walker et al., 1993:71). Individuals within social networks use informal social network activities, such as similar social interests shared between colleagues, as a means of socialising with each other (Van Emmerik, Euwema, Geschiere \& Schouten, 2006:56). According to White (2004:66), it is important that individuals include those who share similar values and interests in their networks. When no common ground exists between individuals within the network, contacts will not be sustainable in the long-term.

Business contacts are often found within social environments. These environments include networking events (Rezac, 2005:114) and evening events (such as drinks or a sit-down dinner). These evening events may take the form of social occasions, but they are valuable opportunities to network (Rezac, 2005:113; Tullier 2004:36; Yeung, 2006:89-90).

\section{PURPOSE AND OBJECTIVES OF THE STUDY}

The primary objective of this study was to investigate the networking practices of businesswomen in Gauteng, South Africa. In order to attain this objective, the following secondary objectives were formulated:

1 to investigate the concept of networking through qualitative research;

2 to determine the motivation behind the networking efforts of businesswomen in Gauteng;

3 to investigate the concept of social networking through qualitative research; and

4 to investigate the contents of Gauteng businesswomen's social networks.

\section{RESEARCH METHODOLOGY}

The research methodology consisted of a literature review and an empirical study. The literature review involved the study of databases such as Emerald and Science Direct, which examined the extent of past research on the concepts of networking and social networking. The empirical study investigated the networking practices of businesswomen in Gauteng, South Africa. Notable aspects of the empirical study include the research design; participants, sampling strategy and interview procedure; data collection; data analysis; trustworthiness of the study; and ethical considerations.

\section{Research design}

The research undertaken in this study is explorative in nature. This type of research design was chosen because limited prior knowledge existed on the topic under investigation (Struwig \& Stead, 2001:7; Tustin, Ligthelm, Martins \& Van Wyk, 2005:84); and insight into the general nature of the topic under investigation was needed (Tustin et al., 2005:84). In-depth interviews were used to investigate the topic under investigation in order to elicit the participants' perceptions on networking and social networking (Marshall \& Rossman, 1999:108).

\section{Participants, sampling strategy and interview procedure}

The sample population in this study consisted of a non-probability purposive voluntary sample of businesswomen who work and live in Gauteng $(n=31)$. The research focused on Gauteng, as it is considered the economic centre of South Africa (SA, 2009). A well-known networker in Gauteng was contacted in order to assist the researcher in gaining the names of businesswomen to invite to the interviews. This well-known networker was introduced to the researcher by one of her own networking 
contacts. Five businesswomen who were willing and had sufficient time to take part in the study were contacted and interviews were scheduled. Thereafter, a non-probability snowball sampling technique was used to gain access to other Gauteng businesswomen with whom interviews were conducted. This was achieved by asking each of the five original participants to identify other Gauteng businesswomen who would possibly be able to participate in the study.

The same agenda was used in every interview, in which the following questions were asked:

1 How do you conceptualise networking and what are the main characteristics of networking?

2 Why do you network; that is, what are your motivations for networking?

3 How do you conceptualise social networking and what are the main characteristics of social networking?

4 Describe the contents of your social network.

The characteristics of the participants are as follows. The majority of the participants $(73.7 \%)$ were White, while $19.6 \%$ were Black and $6.7 \%$ were Indian women. Most of the participants $(43.3 \%)$ were between the ages of thirty-five and forty-four, $26.7 \%$ were between the ages of forty-five and fifty-four, $26.7 \%$ were between the ages of twenty-five and thirty-four, and $3.3 \%$ were under the age of twenty-five. In the main, the participants held a diploma or certificate (38.7\%) or a postgraduate qualification (38.7\%), and were thus mostly representative of the sample. The remainder of the participants held a Bachelor degree $(19.4 \%)$ or a Grade Twelve certificate (3.2\%). A large percentage of the participants were single $(35.5 \%)$, some were divorced $(25.8 \%)$ or married $(22.6 \%)$ and had no children under the age of twelve $(67.7 \%)$. A smaller percentage of women were engaged (3.2\%), widowed (3.2\%) or in a long-term relationship (9.7\%) and had children under the age of twelve (32.3\%). The participants were representative of various industries. The majority of the participants worked in the financial industry $(40.1 \%)$. Others worked in business services (12.1\%), education/training $(9.5 \%)$, human resource consulting $(9.6 \%)$, information technology $(6.3 \%)$, property $(3.2 \%)$, law $(3.2 \%)$, construction (3.2\%), fashion $(3.2 \%)$, tourism $(3.2 \%)$, and $6.4 \%$ of the participants were representative of all industries. During the interviews, one participant felt uncomfortable indicating her ethnicity and another participant felt uncomfortable revealing her age.

\section{Data collection}

In-depth interviews and field notes were used to collect the data. The interviews were audiotaped with the permission of the participants, and field notes, including observational and personal notes, were taken during and directly after each interview. Field notes were taken in order to assist the researcher in facilitating data management and compiling the research results (Hesse-Biber \& Leavy, 2006:258). Following the interviews, the participants were asked to complete a short biographical questionnaire. Data saturation was reached after the twenty-third interview. However, the researcher decided to conduct additional interviews in order to gain a larger number of rich direct quotations that demonstrated the identified themes clearly and to ensure that no new information was overlooked.

\section{Data analysis}

Several steps were followed in analysing the data. These steps included:

1 Organising and preparing the data for analysis, such as typing the field notes and transcribing the interviews (Creswell, 2003:191) - the textual data from the interviews was analysed separately using the theme approach and open coding, as discussed by Creswell (1994:153);

2 Exploring the data - this was done by a first reading of the transcripts in order to gain a general insight into the perceptions expressed in the interviews (Creswell, 2003:191), and thereafter a second reading in order to highlight the most important (Hesse-Biber \& Leavy, 2006:347) and relevant issues with the aim of better understanding the networking practices of businesswomen;

3 Grouping the data into three categories, namely the participants' perceptions, experiences, and recommendations on networking - this assisted the researcher during coding;

4 Coding the data - open coding was used to assign codes to each section of the text that was highlighted as important in the second step (Hesse-Biber \& Leavy, 2006:350);

5 Identifying the major themes (Creswell, 2003:193; Hesse-Biber \& Leavy, 2006:349); 
6 Identifying the sub-themes and additional themes, and identifying relationships amongst themes (Daymon \& Holloway, 2002:237) - the sub-themes and additional themes identified were then placed under the focused main themes;

7 Using a co-coder to ensure correspondence between all the identified themes and sub-themes - the participants' quotations were then used to support the major findings of the study (Creswell, 2003:194);

8 Using member-checking to ensure that the perceptions of the participants had been correctly recorded and interpreted - this was done by presenting the recorded data to the participants in order for them to correct any errors they may have made during the interviews or to correct misinterpretations made by the researcher (Daymon \& Holloway, 2002:96).

\section{Trustworthiness}

In order to ensure that the findings were trustworthy, Guba's model for qualitative research was applied in this study (Krefting, 1991; Lincoln \& Guba, 1985). Guba's model of trustworthiness are used to assess the trustworthiness of qualitative inquiry through describing four general criteria for evaluation of research and then defining each from both a quantitative and a qualitative perspective (Krefting, 1991:214). The criteria used in this study to ensure that the findings were trustworthy included credibility (checking the truth value of the findings), transferability (ensuring applicability of the findings), dependability (ensuring consistency of the findings) and confirmability (ensuring the neutrality of the findings) (Krefting, 1991:215221; Lincoln \& Guba, 1985:219). An overview of the strategies used during the research process in order to ensure trustworthy findings is presented in Table 1.

Table 1:Strategies applied to ensure the trustworthiness of the findings

\begin{tabular}{|l|l|l|}
\hline Criteria & Strategy & Application \\
\hline Credibility & $\begin{array}{l}\text { Data triangulation } \\
\text { (Easterby-Smith, } \\
\text { Thorpe \& Lowe, } \\
2002: 146) \\
\text { Peer examination }\end{array}$ & $\begin{array}{l}\text { Data collection consisted of in-depth interviews and making } \\
\text { field notes. The networking theory was also reviewed. }\end{array}$ \\
\hline Transferability & $\begin{array}{l}\text { Interview techniques } \\
\text { a panel of reviewers (North-West University Ethics Committee) } \\
\text { evaluated the interview agenda. }\end{array}$ \\
\hline Dependability & $\begin{array}{l}\text { Interview techniques such as probing questions, summarising } \\
\text { and paraphrasing were used during the interviews, in order to } \\
\text { increase the credibility of the findings. } \\
\text { Detailed information about the participants, research settings } \\
\text { and methodology was collected, in order to allow other } \\
\text { researchers to transfer the findings of this study. } \\
\text { Participants who were knowledgeable on the concept of } \\
\text { networking were sampled to participate in the study. }\end{array}$ \\
\hline Confirmability & Auditing & $\begin{array}{l}\text { A co-coder assisted the researcher in identifying the research } \\
\text { themes and establishing correspondence between the } \\
\text { identified themes and sub-themes. } \\
\text { The researcher audio-recorded all interviews and took field } \\
\text { notes, which facilitated auditing. }\end{array}$ \\
\hline Confirmability auditing & $\begin{array}{l}\text { The transcriptions and field notes can be made available for } \\
\text { auditing. }\end{array}$ \\
\hline
\end{tabular}

\section{Ethical considerations}

The confidentiality and anonymity of each participant were respected at all times. The confidentiality of the participants was ensured by only the researcher, supervisor and an independent transcriber having access to the audio recordings. No participant names were connected to any data documented during the interviews. Participants were informed about the nature of the study (that is, the background to the study, the research objectives and the process to be followed) before each interview was conducted. Participants were asked to sign consent forms, allowing the researcher to use the collected data. These forms stated that participation was voluntary, participants could withdraw from the study at any point and 
that all the data collected would be handled with confidentiality. During the interviews, the researcher endeavoured to be honest and fair, and to conduct the interviewing process in a respectful manner. No one was discriminated against based on age, sex, ethnicity, religion or language (Struwig \& Stead, 2001:67).

\section{DISCUSSION OF FINDINGS}

Different main themes were identified in terms of the participants' perceptions on networking and social networking. A discussion follows below.

\section{Theme 1: Conceptualisation and characteristics of networking}

Participants perceived networking as a way to interact with other individuals. The following quotation illustrates this finding: "I think networking is being able to interact with other people whether it is a social or business environment." Literature is consistent with this finding in that networking is viewed as the ability to meet with individuals, interact with them and develop relationships (Boe, 1994:9; Lucas, 1994:20; Misner \& Morgan, 2000:13, 20; Tullier, 2004:31; Bannerman, 2006:15).

In addition to this finding, participants further indicated that while networking, individuals interact with each other in order to gain value (such as gaining knowledge, new information and new contacts) from that interaction. The following quotation supports this finding: "So networking for me is being around other people, actively interacting and speaking with them with the intention of being able to gain some knowledge, some new information or even making new contacts." This finding is supported in the literature. Bannerman (2006:15) suggests that networking refers to people meeting with each other and sharing information that has the potential of being beneficial. People meet other individuals and develop relationships with the intention to share ideas and gain referrals, advice, information, support and resources (Boe, 1994:9; Misner \& Morgan, 2000:13).

Participants perceived networking as a means by which information can be shared. The following quotation illustrates this finding: "Networking is an informal means of getting information [and] sharing information that has also got a key role in generating new relationships [and] maintaining new relationships." The literature extensively provides support for this finding. Networking refers to people meeting and sharing information with each other (Boe, 1994:9; Misner \& Morgan, 2000:13; Tullier, 2004:30; Bannerman, 2006:15).

The participants perceived networking to be a learnable skill. The following quotation illustrates this finding: "Networking is something that can be learnt." This finding is supported in the literature. Networking is a learnable skill (Yeung, 2006:17) and entails social skills, which can be acquired by anyone who is willing and ready to work hard (Boe, 1994:7, 8).

Furthermore, the participants felt that networking is not restricted to any one location or environment. Networking can take place in any situation or environment and at any time. The participants responded as follows: "I see networking as something that can be done in all environments all the time." This finding is consistent with the literature. Networking can be adapted to any situation where people meet (Yeung, 2006:22). Individuals need to be open to any networking opportunities as people interact with each other anywhere (for example, at the dentist, beauty salons or gyms (Tullier, 2004:37).

In addition to this finding, participants indicated that networking can take place in formal or informal situations. The following quotation supports this finding: "Networking can be on a formal basis or informal basis." This finding is supported in the literature. Tullier (2004:31) states that network opportunities can arise from formal and informal situations. Networking can involve an informal conversation with a friend, family or co-worker, an e-mail sent to a colleague or a formal appointment scheduled with an individual unknown to the individual concerned (Tullier, 2004:32).

Participants also indicated that networking involves building and maintaining network relationships. For example, the participants stated: "And I see networking more as being about building relationships, not just initiating [relationships, but] building relationships and maintaining those relationships, making sure 
that it is sustainable so that the network doesn't dry up." The literature extensively provides support for this finding. Networking does not only involve developing relationships but also involves maintaining these relationships through interaction (Boe, 1994:9; Tullier, 2004:30; Lindenfield \& Lindenfield, 2005:13). Additional to this finding, participants mentioned that networking involves leveraging any relationship that have been build, that the relationships that are built during networking are mutually beneficial and that networking should involve helping other people. Firstly, the participants concluded that networking involves leveraging any relationships that have been built. No emotive attachment needs to be made with the involved role-players before making use or benefiting from those networking relationships. The following quotation supports this finding: "... it is leveraging relationships, it is not making an emotional attachment to someone, it is leveraging an acquaintance." This finding is disputed by Boe (1994:72), who claims that treating relationships in an underhanded manner is an obstacle to successful networking. In networking, it is more important to focus on the relationship than the outcomes of that relationship. Individuals must make an emotive connection in order to establish a bond with the other person he or she networks with before utilising that relationship (Lindenfield \& Lindenfield, 2005:183; 191).

Regarding this finding, participants also mentioned that networking entails establishing long-term relationships and that establishing these relationships takes some time. The following quotations illustrate this finding: "It is more like a long-term relationship." and "I think networking is meeting with people with a view of building relationships. It is not something that is a quick thing; you cannot meet somebody and say I am really networking." This finding is supported in the literature. According to White (2004:5), networking occurs when people meet with others with the intention to develop long-term relationships for mutual gain or benefit. Building these relationships requires time, commitment and effort (Kay, 2004:10) and therefore, an individual must be focused and patient in building these networks (Kay, 2004:79).

The participants further indicated that networking gives like-minded people the opportunity to pursue common interests and gain support. The following quotation supports this finding: "They allow a space for like-minded people to pursue a common interest and gain support and understanding as well as camaraderie through this medium." This finding is supported in the literature by Nierenberg (2005:14), who recommends that individuals include like-minded people in their network. The individuals with whom it is the easiest to interact are those who have common interests and ambitions and share similar life experiences with the individual concerned, as such common ground facilitates networking opportunities.

Secondly, the participants indicated that the relationships built during networking are mutually beneficial. In networking, both parties may benefit from the interaction. The following quotation supports this finding: "... to make a connection with various people that you would not normally do on a day-to-day basis but to the benefit of both parties." This finding is supported in the literature. Networking is viewed as the process of building relationships that are mutually beneficial (Boe, 1994:9; Tullier, 2004:9, 30; Lindenfield \& Lindenfield, 2005:13).

Regarding this finding, participants also mentioned that networking needs to be a reciprocal process; both parties need to work at the relationship and help each other to benefit from that relationship. The following quotation illustrates this finding: "I think it has to be a two-way network as well, that you are not just doing everything yourself all the time." This finding is supported in the literature. According to Lindenfield and Lindenfield (2005:75) reciprocity is a basic principle of networking and entails both parties being willing to give and receive.

Thirdly the participants indicated that networking should involve helping other people. The following quotation supports this finding: "Networking should be about helping other people." No networking literature was found that supports this unique finding.

Regarding this finding, participants stated that individuals need to assist people in their network before utilising that networking relationship. Participants felt that networking should not involve using people in order to gain something, and stated that networking should not entail using the people within the network to gain benefits from them or the networking interaction. The following quotation supports this finding: "... so I guess most people see networking as building relationships in order to get business or to learn 
something from it. I guess networking is about the relationships, but it is about the purpose of that relationship. You are not just running around and trying to see what you can get from people." This finding is supported in the literature. Networking does not involve asking people for jobs or using them to gain additional business customers. Asking a network contact directly for a job is seen as an obstacle in the way of successful networking (Tullier, 2004:8-9; Yeung, 2006:168).

Participants also mentioned that networking entails an individual giving to the people in his or her network. Participants suggested that networking is an interaction that allows for the provision of resources and assistance to others. Therefore, individuals need to identify the needs (such as advice or business contacts) of the person with whom they are networking, and assist him or her in gaining what they require. The following quotation supports this finding: "... [Networking is] a situation where you are in to also give to other people. It is a wonderful opportunity to also provide people and to assist people." This finding is supported in the literature. In networking, it is important to remember that the other person also has needs that need to be fulfilled (Tullier, 2004:289). Individuals should give to the people they network with and remember that he or she will not always instantly receive when they give, but they should give with the knowledge that the exchange will be mutually beneficial at some point in the future (Lindenfield \& Lindenfield, 2005:75).

\section{Theme 2: Reasons and motivations for networking}

The participants stated that the networking efforts of individuals are motivated. Networking has an underlying objective to achieve the desired networking outcomes. The following quotation illustrates this finding: "I see networking as a form of interaction, but with a goal." This finding is supported in the literature. Networking should be done with an objective in mind in order for the networker to achieve his or her desired outcomes (Nierenberg, 2005:1; Yeung, 2006:19).

The participants stated that networking must be focused in order to gain from the interaction. If the interaction is too vague (for example, if there is no clear objective to networking), nothing will be gained from the interaction. The following quotation supports this finding: "So there is benefit that you gain out of networking, but it must be a bit focused, if it is too vague nothing tends to happen." This finding is supported in the literature. Networkers need to have a goal in mind when networking (Yeung, 2006:19). The participants perceived networking as a marketing tool. The following quotation supports this finding: "I see networking as a marketing tool." This is supported in the literature. Networking is a marketing tool (White, 2004:68; Rezac, 2005:120; Bannerman, 2006:17).

Additional to this finding the participants stated that they use networking to market themselves and their products or services. The participants firstly indicated that they use networking to market themselves. Networking is a means by which to gain opportunities related to their careers and/or businesses aspirations. The following quotation supports this finding: "To me networking is interacting with various individuals who would possible be in the same industry or across industries. It is meeting on a social level with key individuals either internally or externally in order to market oneself, because that is the object of networking." This finding is supported in the literature. Kay (2004:34) suggests that networking provides the opportunity for individuals to market themselves. If individuals are honest regarding their strengths, talents, skills, creative ideas and successes (Lindenfield \& Lindenfield, 2005:25), networking can be a proactive form of self-marketing that holds benefits for all of those involved (White, 2004:6).

Secondly, the participant indicated that they use networking to market their products or services; they do not make use of advertising but rather use people to inform other individuals about their products or services. The following quotation illustrates this finding: "... the definition for me is where you have a specific product or service that you want to provide and where you then make use of people to tell other people about [your product or service], not necessarily making use of advertising." This finding is supported in the literature. White (2004:6) suggests that when networking is conducted in the right environment, it offers the opportunity to sell products or services to other people.

Participants perceived various business motivations behind their networking efforts. According to the participants, networking lends assistance and support. Networkers can assist each other by providing business leads and support (for example, work support). The following quotation supports this finding: 
"[Networking is] a process where the formality of business is removed and the intention clear at the same time that business is the priority and where one party can assist the other directly or indirectly through support or leads." This finding is supported in the literature. Boe (1994:14) suggests that networking establishes relationships that are mutually supportive and empowering and that networking serves as a support system. Strong personal networks can be used to gain support for challenges experienced by individuals within the business environment (Misner \& Morgan, 2000:21).

Participants mentioned that they utilise networking to make new business contacts. The following quotation illustrates the finding: "I see networking as a vehicle to extend my contacts, especially business contacts." This finding is supported in the literature. Yeung (2006:11) suggests that networking is a tool that can assist individuals in building contacts.

Participants further mentioned that networking offers synergy through combined action and encourages business creation. The following quotation illustrates this finding: "[Networking] encourages synergy and business creation." This finding is supported in the literature. Lindenfield and Lindenfield (2005:24-26) state that networking is used when an individual wishes to launch a new business or charitable project, search for new investors or a new partner for forming strategic alliances, or expand a business's customer base.

Participants indicated that networking is a way in which potential business is gained. The following quotation supports this finding: "... in networking your aim will be to gain knowledge, possible new contacts, and potential business." This finding is supported in the literature. Kay (2004:34) suggests that networking is a process of building relationships with a diverse group of people with the intention to increase business opportunities.

Participants perceived various personal motivations behind networking. The participants perceived networking as a means by which information can be gained. The following quotation illustrates this finding: "Networking is obviously using the people or the resources that you have to get to know people or get information that you do not necessarily have currently." This finding is supported in the literature. Rezac (2005:143) states that networking entails exchanging knowledge and information. Good networkers are both seekers and sources of knowledge.

The participants also mentioned that networking facilitates learning and growth through interaction. The following quotation supports this finding: "[Networking involves] any opportunity to learn, grow and influence [that is] created by direct or indirect contact with other people that you can relate to." This finding is supported in the literature. Networking facilitates the mutual exchange of information, support and advice that lead to the growth, success and happiness of networkers (Tullier, 2004:30).

\section{Theme 3: Conceptualisation and characteristics of social networking}

Participants indicated that social networking takes place in a more relaxed, informal environment than business networking. The following quotation supports this finding: "Social networking is more in a social environment, getting to know people in a more relaxed atmosphere and it is obviously got to do with more than one person. I do not think it is as intentional as your more formal networking." This is supported in the literature. According to Lindenfield and Lindenfield (2005:13), relationships are built through social interaction. Individuals build lifelong friendships through opportunities created by meeting with others in social environments (Nierenberg, 2005:27).

Additional to this finding, participants mentioned that social networking takes place when people are having a drink or dinner together, or having a braai (barbeque), or are seeking a romantic date. Firstly, the participants mentioned that social networking takes place when people are having a drink or dinner together. The following quotation illustrates this finding: "[Social networking takes place] in a social setting such as dinner or drinks where business may not necessarily be the aim but dating for instance." This finding is supported in the literature. Lindenfield and Lindenfield (2005:230) state that having meals (for example, lunch and dinner) with colleagues and clients is an informal way of building relationships. 
Secondly, the participants mentioned that social networking takes place in a social setting in which people are having a braai (barbeque). The following quotation illustrates this finding: "Social networking is when you are sitting at a braai or having a dinner or you have been invited as a guest to somebody else's event." No literature was found to support this unique finding.

Thirdly, the participants stated that social networking refers to the activity in which individuals engage in seeking a romantic date. The following quotation illustrates this finding: "Social networking for me is more where you are looking for dates." This finding is supported in online social networking literature. Social networking allows individuals to connect with others for various purposes, including dating, discussing music or films, conducting business or developing affiliate and business partners (Power et al., 2006:58).

Furthermore, participants indicated that social networking is a way to build new friendships. The following quotation illustrates this finding: "[Social networking] is a good way to make new friends and also just being able to let down and party a little." This finding is supported in the literature. Developing new friendships is seen as a social motivation behind networking (Bannerman, 2006:29; Boe, 1994:9). Being a networker necessarily entails being sociable and this cannot be achieved in the absence of friends (Bannerman, 2006:29).

Participants mentioned that social networking takes place in a location or event at which people with similar interests gather. The following quotation supports this finding: "It is about sharing common values, especially trust and integrity and off course a sense of humour helps." This is supported in the literature. Van Emmerik et al. (2006:56) state that informal social network activities require sharing common social interests with other people. These social interests facilitate socialising with other people.

Additional to this finding, it was concluded that social networking refers to people pursuing similar interest, such as community projects and that clubs, such as book clubs form part of individuals' social networking. Firstly, it was concluded that social networking refers to people pursuing similar interests, including community projects. The following quotation supports this finding: "Social networking just extends your context, for example business networking would be just within the business context, but social networking may be where you meet people that you can get involved in community projects [with] or you can get involved in clubs." This finding is supported in the literature. Lindenfield and Lindenfield (2005:233) suggest that local community involvement is viewed as a good way to make career connections. Strong connections are built when people do charitable work. Involvement in these activities displays characteristics (for example, trust) that render individuals attractive candidates for networking.

Secondly, it was concluded that clubs, including book clubs, form part of the participants' social networking. The following quotations support this finding: "I believe [social networks] are like clubs." and "... [for example] book clubs." This is supported in the literature. Lindenfield and Lindenfield (2005:232233) suggest that clubs (for example, sports clubs and health clubs) are good ways for an individual to extend their social network.

Furthermore, participants indicated that there is a difference between social networking and business networking in that the subject matter and the intention of the interactions differ. The following quotation supports this finding: "The intention and content of the conversation is different though the outcomes are very much the same." This is supported in the literature. White (2004:14) posits that the intention of networking differs when individuals have different objectives. For example, the intention and thus subject matter of the networking of a networker wishing to enhance their profile will differ to that of a networker starting a new business.

Additional to this finding, it was concluded that business networks are more structured than social networks. The following quotation illustrates this finding: "With business networks you get to be much more structured." This is supported in the literature. Business networking or strategic networking takes place when individuals are focused in the way they network. They purposefully seek out individuals with whom they wish to build relationships (Lindenfield \& Lindenfield, 2005:15-17). 
Participants also mentioned that the difference between business networking and social networking lies in the structure of the networks. Business networking is formal and social networking is informal. The following quotation illustrates this finding: "... business networking would be a more formal and targeted situation." This is supported in the literature. According to Ibarra (1993:58), formal networks are sets of formally specified relationships, and informal networks involve more flexible and social interactions. Business networking is more focused and strategic (Lindenfield \& Lindenfield, 2005:15-16).

Additional to this finding, participants perceived business networking to be goal-orientated and social networking to be recreation oriented. The following quotations illustrate this finding: "One is business goal-orientated and the other entertainment." and "... the aim of social networking is to unwind and relax with friends in an informal setting." This is supported in the literature. Lindenfield and Lindenfield (2005:183) state that networking in business is seen as a business activity and not an activity done for pleasure. Within informal networks, the interaction between individuals is more flexible (Ibarra, 1993:58).

However, although various differences were noted, the participants also noted that social and business networking have similarities too. The following quotation illustrates this finding: "Well nowadays in business I think [business networking and social networking] is very similar." This finding is disputed in the literature by lbarra (1993:58). She suggests that within organisational research, a distinction between formal (business) and informal (social) networks is commonly made. A formal network includes a set of formal relationships between superiors and subordinates who interact to accomplish organisational tasks, whereas informal networks include relationships that are at a more discretionary level. Within informal networks, the topics can be social, work-related or a combination of both.

\section{Theme 4: Contents of social networks}

Various elements were noted to be part of individuals' social networks. Participants mentioned that social networks include supportive people. The following quotation supports this finding: "... I think that particularly in your social network it is really people that care about you and that kind of love and support you." This is supported in the literature. Social networks include people that are supportive (Walker et al., 1993:71), such as friends, colleagues and acquaintances (Rezac, 2005:24).

Participants indicated that people with the same values are included in social networks. The following quotation illustrates this finding: "... I think that it is important that they are genuine, that they have a kind of value system that I can relate to. I am not saying that all their values have to be the same as my values, but they [must] have other values that I can relate to." This finding is supported in the literature. White (2004:66) suggests that it is important for individuals to include people in their network who share the same values. If there is no common ground between the individuals within the network, the contacts will not be sustainable in the long-term.

Participants indicated that business contacts can be made in social environments. The following quotation supports this finding: "... sometimes you could go to a social networking event and you find some business contacts there." This finding is supported in the literature. Valuable contacts can be developed in social settings, such as health clubs, cocktail parties and neighbourhood meetings (Tullier, 2004:36). An individual's network of social relationships can potentially be utilised for commercial exchanges, working alliances and career advice (Lindenfield \& Lindenfield, 2005:14).

\section{CONCLUSION}

The primary objective of this study was to investigate the networking practices of businesswomen in Gauteng. In order to attain this objective, it was firstly necessary to investigate the businesswomen's perceptions of networking. The study found that businesswomen had various perceptions of the concept of networking, and that these perceptions help to provide them with background and clarity on the subject. Businesswomen are responsible for the success of their own networking efforts and for the energy they put into their networking relationships. They need to be aware of these networking perceptions and incorporate these into their networking practices, at networking events or in other networking situations. It is vital for businesswomen to network effectively (for example to maintain their relationships), in order to ensure the establishment of a balanced network of relationships that can 
potentially lead to long-term mutual beneficial interactions. It is also vital for businesswomen to establish a relationship before leveraging the networking relationship; and to assist individuals with whom they network before attempting to benefit from the relationship.

Secondly, it was important to look at the various reasons and motivation behind the Gauteng businesswomen's networking. It was concluded that networking is initiated by a specific motivation. The motivation can be personal or business-related. In order for businesswomen to ensure that their networking outcomes are reached, they need to have clear networking objectives. This conclusion implies that businesswomen are responsible for their own networking efforts, in that they determine their own need to network. Businesswomen are also responsible for the energy they put into their networking efforts to achieve their desired networking outcomes.

Thirdly, it was important to investigate the businesswomen's perceptions of social networking. The main finding is that there are various perceptions of the concept of social networking. These findings help to provide businesswomen with background information on the concept of social networking. Businesswomen are given background on when to network socially and what their social networking efforts can be utilised for. The finding further implies that businesswomen are responsible for their own social networking efforts and for how effectively they utilise those opportunities. The finding also suggests that businesswomen need to become aware of the various perceptions of social networking and incorporate these into their social networking practices to ensure the success of their social networking efforts. It is also vital for businesswomen to clearly establish a goal for their social networking and expend energy into their networking efforts in order to reach this goal. Another important aspect that businesswomen need to consider is to view braais as social networking opportunities and to recognise that social networking can be a means of seeking romantic dates, and utilise such opportunities to assist them in attaining their social networking goals. Businesswomen also need to take note of the differences that exist between social and business networking and bear these in mind when networking in order to achieve their desired networking outcomes.

Fourthly, it was important to investigate the contents of businesswomen's social networks. It was concluded that social networks consist of supportive people and individuals with similar values, and that business contacts can be found in social environments. This finding provides businesswomen with a starting point of the people to include in their social networks. It further provides businesswomen with background information on the social settings in which business connections can be established. The people included in businesswomen's social networks can influence the success of their social networking efforts. Therefore, it is important to establish social networks with the right people. Businesswomen need to include the right combination of individuals in their social networks, and these individuals need to be selected in accordance with the businesswomen's desired social networking outcomes.

\section{LIMITATIONS}

Various limitations were noted during the research process, which may have influenced the research outcomes. These included:

1 Owing to their involvement in their personal and professional lives, the businesswomen found it difficult to fit the interviews into their busy schedules and had limited time to participate in the interviews. It appeared that the interviews were not highly prioritised by the participants.

2 Most of the interviews took place at a central coffee shop. During the interviews, the shop was noisy at times, which made the recording of the interviews difficult. There were additional disturbances during some recordings, including interaction with the waiter, loud music and a noisy parking lot.

3 Although a heterogeneous sample was sought for this study, the population mostly consisted of White women who had no children under the age of twelve. Furthermore, the sample only included businesswomen in Gauteng. As a result, the research findings cannot be generalised to businesswomen in other provinces, for example. 


\section{RECOMMENDATIONS}

Networking should be taught at business schools and should form part of business modules at universities, as the concepts of networking and social networking are vital for students in entrepreneurship, marketing and business studies. If students are familiar with these concepts, they will be able to integrate these into their personal and professional lives successfully (for example, utilising networking to market their profile in order to become employed or to obtain a business opportunity).

Businesswomen need to become aware of the concepts of networking and social networking. Therefore, training initiatives should be established within organisations. Organisations should recognise the importance of businesswomen networking, and assist them in becoming more aware of the concepts of networking and social networking and the way in which they can be utilised to help achieve their personal or professional goals. Organisations could accomplish this through establishing training courses. Training courses should focus on:

1 the interactive aspect of networking;

2 the importance of maintaining networking relationships;

3 networking as a means of sharing information that is mutually beneficial;

4 networking as a skill that can be learnt and the manner in which these skills can be acquired;

5 openness towards networking opportunities in any environment;

6 the motivations for networking;

7 the importance of establishing clear networking goals;

8 establishing valuable connections within social environments;

9 the importance of social networking objectives; and

10 providing businesswomen with a basis of knowledge on where to network socially and the types of people to include in their social network.

This study enables other researchers to use the research as the basis for conducting a quantitative study for future research in which the identified themes can be developed into a measuring instrument (questionnaire) for further investigation of the networking practices of businesswomen.

\section{REFERENCES}

BANNERMAN, L. 2006. Networking in 90 minutes: networking to improve your netw£rk! Cirencester: Management Books 2000. $113 \mathrm{p}$.

BOE, A. 1994. Networking success: how to turn business and financial relationships into fun and profit. Deerfield Beach, FL: Health Communications. 222 p.

BOE, A. \& YOUNGS, B.B. 1989. Is your 'net' working? A complete guide to building contacts and career visibility. NY: Wiley. $250 \mathrm{p}$.

BRAUDE, D. \& FRANCISCO-LA GRANGE, F.H. 1993. Support systems in the life situation of children of divorce. Pretoria: HSRC. 64 p.

BUSINESSWOMEN'S ASSOCIATION. 2010. BWA South Africa women in leadership - census 2010. http://www.bwasa.co.za/Portals/4/docs/BWACensus2010Report.pdf Date of access: 22 Sept. 2010.

CRESWELL, J.W. 1994. Research design: qualitative and quantitative approaches. Thousand Oaks, CA: Sage. $228 \mathrm{p}$.

CRESWELL, J.W. 2003. Research design: A qualitative, quantitative and mixed method approaches. 2nd ed. Thousand Oaks, CA: Sage. 246 p.

DAYMON, C. \& HOLLOWAY, I. 2002. Qualitative research methods in public relations and marketing communications. London: Routledge. 293 p. 
EASTERBY-SMITH, M., THORPE, R. \& LOWE, A. 2002. Management research: an introduction. $2^{\text {nd }}$ ed. Thousand Oaks, CA: Sage. 194 p.

FORRET, M.L. \& SULLIVAN, S.E. 2002. A balanced scorecard approach to networking: a guide to successfully navigating career change. Organisational Dynamics, 31(3):245-258, Winter.

GOTTLIEB, B.H. 1981. Social networks and social support. Beverly Hills, CA: Sage. 304 p.

HESSE-BIBER, S.N. \& LEAVY, P. 2006. The practice of qualitative research. Thousand Oaks, CA: Sage. $404 \mathrm{p}$.

IBARRA, H. 1993. Personal networks of women and minorities in management: a conceptual framework. Academy of Management Review, 18(1):56-87, Jan.

KAY, F. 2004. Brilliant business connections: how powerful networking can transform you and your company's performance. Oxford: How To Books. 209 p.

KREFTING, L. 1991. Rigor in qualitative research: the assessment of trustworthiness. American Journal of Occupational Therapy, 45(3):214-222, Mar.

LAHTINEN, H.K. \& WILSON, F.M. 1994. Women and power in organizations. Executive Development, 7(3):16-23. Available: Emerald. Date of access: 13 Oct. 2009.

LINCOLN, Y.S. \& GUBA, E.G. 1985. Naturalistic inquiry. Newbury Park, CA: Sage. 416 p.

LINDENFIELD, G. \& LINDENFIELD, S. 2005. Confident networking for career success and satisfaction. London: Piatkus. $280 \mathrm{p}$.

LINEHAN, M. 2001. Networking for female managers' career development: empirical evidence. Journal of Management Development, 20(10):823-829. Available: Emerald. Date of access: 11 May 2009.

LUCAS, R.W. 1994. Effective interpersonal relationships. NY: McGraw-Hill. 100 p.

MARCINKUS, W.C., WHELAN-BERRY, K.S. \& GORDON, J.R. 2007. The relationship of social support to the work-family balance and work outcomes of midlife women. Women in Management Review, 22(2):86-111. Available: Emerald. Date of access: 20 Mar. 2009.

MARSHALL, C. \& ROSSMAN, G.B. 1999. Designing qualitative research. 3rd ed. Thousand Oaks, CA: Sage. $224 \mathrm{p}$.

MICHELLI, D. \& STRAW, A. 1997. Successful networking. Hauppauge, NY: Barron's Educational Series. $103 \mathrm{p}$.

MISNER, I.R. \& MORGAN, D. 2000. Masters of networking: building relationships for your pocketbook and soul. Marietta, GA: Bard Press. $335 \mathrm{p}$.

NIERENBERG, A.R. 2005. Million dollar networking: the sure way to find, grow, and keep your business. Sterling, VA: Capital Books. 260 p.

REZAC, D. 2005. Work the pond! Use the power of positive networking to leap forward in work and life. NY: Prentice-Hall. 203 p.

SA see SOUTH AFRICA.

SOUTH AFRICA. 2009. Gauteng. http://www.info.gov.za/aboutsa/provinces.htm\#gauteng. Date of access: 23 Sept. 2010. 
STRUWIG, F.W. \& STEAD, G.B. 2001. Planning, designing and reporting research. Cape Town: Pearson. $279 \mathrm{p}$.

TRAVERS, C., PEMBERTON, C. \& STEVENS, S. 1997. Women's networking across boundaries: recognizing different cultural agendas. Women in Management Review, 12(2):61-67. Available: Emerald. Date of access: 13 Oct. 2009.

TULLIER, L.M. 2004. Networking for job search and career success. 2nd ed. Indianapolis, IN: JIST Works. $372 \mathrm{p}$.

TUSTIN, D.H., LIGTHELM, A.A., MARTINS, J.H. \& VAN WYK, H. 2005. Marketing research in practice. Pretoria: Unisa Press. $749 \mathrm{p}$.

VAN EMMERIK, I.J.H., EUWEMA, M.C., GESCHIERE, M. \& SCHOUTEN, M.F.A.G. 2006. Networking your way through the organization: gender differences in the relationship between network participation and career satisfaction. Women in Management Review, 21(1):54-66. Available: Emerald. Date of access: 18 Aug. 2008.

WALKER, M.E., WASSERMAN, S. \& WELLMAN, B. 1993. Statistical models for social support networks. Sociological Methods and Research, 22(1):71-98, Aug.

WHITE, H. 2004. Networking for business success. Great Britain: Writers Printshop. 75 p.

YEUNG, R. 2006. The rules of networking. Singapore: Marshall Cavendish Business. $180 \mathrm{p}$. 